\title{
Perintisan Taman Baca Tunas Merapi sebagai Upaya Pengembangan Generasi Gemar Membaca di Dusun Druwak Desa Logede Kecamatan Karangnongko Klaten
}

\author{
Eko Didik Widianto ${ }^{1}$, Wahyu Krisna Hidayat ${ }^{2}$, Aris Sugiharto ${ }^{3}$ \\ ${ }^{1}$ Teknik Sistem Komputer, Universitas Diponegoro \\ ${ }^{2}$ Teknik Geologi, Universitas Diponegoro \\ ${ }^{3}$ Teknik Informatika, Universitas Diponegoro \\ didik@live.undip.ac.id
}

\begin{abstract}
Reading Park in the community is one of the important instruments to support community's need for information and knowledge. This dedication activity aimed to pioneer the development of Reading Park in the bamlet of Druwak. This Reading Park contained a collection of books that could be accessed by the public and had been classified based on its subject. This Reading Park was expected to help the community, especially children and parents in Druwak hamlet, to realize the community of Druwak who like reading, so as to open the perception and orientation of thought towards literacy education.
\end{abstract}

Keywords: Reading Park, Infomation Access, Reading Culture

\section{Pendahuluan}

Dusun Druwak berlokasi di daerah lereng Merapi yang berada di radius $10 \mathrm{~km}$ dari puncak Merapi. Dusun yang terletak di desa Logede Kecamatan Karangnongko, Klaten ini letaknya cukup terpencil karena letaknya yang berada di ujung desa dan diapit oleh 3 jurang di sisi barat, selatan, dan timur. Kondisi tersebut mengakibatkan dampak yang serius bagi masyarakatnya dimana kondisi masyarakat dusun Druwak lebih tertinggal dibanding masyarakat dusun lain. Hal itu berdampak pula pada terbatasnya persepsi dan orientasi pemikiran masyarakat Druwak. Pendidikan belum disadari sebagai hal yang penting bagi masyarakat Druwak. Hal ini juga disebabkan oleh belum tersedianya sarana dan prasarana bagi masyarakat Druwak untuk mencari sumber informasi dan menambah wawasan melalui membaca.

Salah satu cara untuk meningkatkan kesadaran masyarakat dan membuka wawasan mengenai dunia, khususnya untuk generasi muda, adalah dengan membaca. Membaca adalah kegiatan seseorang dengan menggunakan pengamatan melalui mata untuk menerjemahkan dan menginterpretasikan tanda atau lambang di atas kertas atau bahan lainnya. Jadi membaca merupakan proses ingatan, penilaian, pemikiran, pengkhayalan, pengorganisasian pemikiran dan 


\section{ENGAGEMENT}

Gurnal Pengabdian Kepada Masyarakat

ISSN: 2579-8375 (Print)

ISSN: 2579-8391 (Online)

pemecahan masalah. Membaca merupakan alat untuk belajar dan untuk memperoleh kesenangan, informasi yang terkandung dalam suatu bacaan sehingga mendapat pengetahuan dan pengalaman untuk memenuhi kebutuhan manusia atau seseorang ${ }^{1}$. Budaya baca bagi setiap warga menjadi prasyarat penting dan mendasar untuk mewujudkan bangsa yang maju. Melalui budaya baca, mutu pendidikan dapat ditingkatkan sehingga kualitas sumber daya manusia akan dapat ditingkatkan. Pendidikan seumur hidup (long life education) juga dapat diwujudkan karena dengan kebiasaan membaca seseorang dapat mengembangkan dirinya sendiri secara terusmenerus sepanjang hidupnya ${ }^{2}$.

Dalam era informasi sekarang ini, kemajuan dapat dicapai oleh suatu bangsa jika bangsa itu memiliki budaya baca. Dalam rangka membangun masyarakat membaca dalam mewujudkan masyarakat pembelajar sepanjang hayat, arah kebijakan Pembangunan Pendidikan Nasional 20102014 yang tertuang pada Peraturan Menteri Pendidikan Nasional No.48 Tahun 2010 adalah penguatan dan perluasan budaya melalui penyediaan taman bacaan masyarakat, bahan bacaan dan sumber informasi lain yang mudah, murah, dan merata serta sarana pendukungnya ${ }^{3}$. Pengelolaan taman baca merupakan salah satu usaha untuk meningkatkan kualitas pendidikan, yang termasuk dalam pengelolaan pendidikan ${ }^{4}$.

Melihat penjelasan dan kenyataan di atas, tindakan nyata perlu dilakukan untuk mewujudkan masyarakat yang gemar membaca. Kegiatan pengabdian masyarakat ini mempunyai program merintis pendirian taman baca di dusun Druwak. Program perintisan taman baca diharapkan dapat membantu masyarakat, khususnya anak-anak dan orang tua di dusun Druwak untuk mewujudkan masyarakat Druwak yang gemar membaca sehingga dapat menimbulkan perubahan dalam persepsi dan orientasi pemikiran yang ada menjadi lebih baik, yaitu kesadaran masyarakat tentang pentingnya pendidikan dapat meningkat.

${ }^{1}$ Kamah, Idris dkk., "Pedoman Pembinaan Minat Baca", Jakarta: Perpustakaan Nasional RI, 2002.

2 Kamsul, Khotijah. "Strategi Pengembangan Minat dan Gemar membaca". 2011. Diakses: 16 Oktober http://www.academia.edu/download/51918409/STRATEGI_PENGEMBANGAN_MINAT_BACA.pdf

${ }^{3}$ Kementrian Pendidikan dan Kebudayaan. "Petunjuk Teknis Pengajuan dan Pengelolaan Taman Bacaan Masyarakat Bantuan Perluasan dan Penguatan Taman Bacaan Masyarakat (TBM)". Jakarta: Direktorat Pembinaan Pendidikan Masyarakat Direktorat Jenderal Pendidikan Anak Usia Dini, Nonformal, dan Informal, 2012.

4 Arikunto, Suharsimi. "Prosedur Penelitian: Suatu Pendekatan Praktek". Edisi Revisi. Jakarta: Rineka Cipta, 2010.

Volume 2, Number 1, Mei 2018|72 Inisiasi Taman Baca Tunas Merapi sebagai Upaya Mencetak Generasi Gemar Membaca di Dusun Druwak Desa Logede Kecamatan Karangnongko Klaten 


\section{ENGAGEMENT}

Gurnal Pengabdian Kepada Masyarakat

ISSN: 2579-8375 (Print)

ISSN: 2579-8391 (Online)

\section{Metode}

Kegiatan pengabdian ini selain menggunakan metode ABCD juga disajikan sebagai penelitian kualitatif, yaitu dari data dan fakta yang diperoleh dalam penelitian ditarik kesimpulan dalam bentuk kalimat pernyataan serta hasil penelitian dapat memberikan gambaran tentang keadaan yang terjadi pada saat penelitian. Penelitian kualitatif ini menyajikan data yang diperoleh secara lebih lengkap, lebih mendalam, kredibel, dan bermakna ${ }^{5}$.

Pendekatan yang digunakan dalam penelitian ini menggunakan pendekatan penelitian kualitatif dengan metode deskriptif. Pendekatan dilakukan dengan mendeskripsikan fenomena yang terjadi dalam masyarakat, mencoba membandingkan dan menemukan kondisi sosial yang sesungguhnya ada di dalam masyarakat, khususnya masyarakat dusun Druwak, Desa Logede, Karangnongko Klaten. Permasalahan yang dibahas dalam penelitian ini tidak berhubungan dengan angka-angka, akan tetapi menyangkut pendeskripsian, penguraian dan penggambaran suatu masalah yang sedang terjadi. Penelitian deskriptif ini bertujuan agar peneliti dapat mendeskripsikan secara jelas dan terperinci tentang taman baca Tunas Merapi. Metode kualitatif utama yang digunakan adalah observasi dan tanya jawab secara langsung kepada masyarakat

Taman baca ini akan mengikuti kriteria, yaitu tersedianya ruangan untuk membaca, diskusi, bedah buku, menulis dan kegiatan sejenis yang dilengkapi dengan bahan bacaan dan sarana prasarana yang ada serta didukung oleh pengelola sebagai motivator taman bacaan (Sobri, 2010). Taman bacaan yang menyediakan buku untuk menarik minat baca akan memenuhi persyaratan dari Five Laws of Library Science, yaitu tersedianya buku untuk digunakan dan membuatnya dapat diakses oleh semua orang ${ }^{6}$. Pembaca akan mendapatkan manfaat dari hasil membacanya. Keberadaannya di tengah tengah masyarakat adalah sebagai alat untuk meningkatkan minat dan memenuhi kebutuhan membaca bagai warga masyarakat ${ }^{7}$.

Kegiatan perintisan taman baca Tunas Merapi dilakukan mulai dari tanggal 17 Juli - 15 Agustus 2017. Mitra kegiatan adalah kelurahan Logede, Kec. Karangnongko dan Kelompok Bermain (KB) Tunas Merapi. Kegiatan dibagi dalam 4 tahapan, yaitu sebagai berikut: 1) Observasi mengenai minat baca masyarakat; 2) Pembangunan taman baca; 3) Pengadaan bahan bacaan, dan 4) Pengolahan koleksi taman baca.

5 ibid

6 Ranganahan, S. R. "The Five Laws of Library Science". 1931. Diambil dari https://babel.hathitrust.org/cgi/pt?id=uc1.\$b99721. [Accessed 16 Oct. 2017]

7 Sobri. Dkk. "Pengelolaan Pendidikan". Yogyakarta: Multi Pressindo, 2009.

Volume 2, Number 1, Mei 2018|73 Inisiasi Taman Baca Tunas Merapi sebagai Upaya Mencetak Generasi Gemar Membaca di Dusun Druwak 


\section{Hasil dan Pembahasan}

Keselurahan tahapan kegiatan perintisan taman baca Tunas Merapi telah dilakukan oleh tim pengabdian kepada masyarakat Tunas Merapi sebagai salah satu program multidisiplin. Tim terdiri atas 3 orang dosen dan 11 mahasiswa sebagai tim lapangan Fakultas Teknik, Fakultas Perikanan dan Ilmu Kelautan, Fakultas Ekonomi dan Bisnis, Fakultas Psikologi, Fakultas Sains dan Matematika, serta Fakultas Ilmu Budaya.

\section{Observasi Minat Baca Masyarakat}

Observasi minat baca masyarakat dilakukan dengan tanya jawab kepada masyarakat sekitar di dukuh Druwak, yaitu sebanyak 24 orang dan termasuk pengajar KB Tunas Merapi. Tanya jawab ini bertujuan untuk menggali pengetahuan masyarakat tentang pentingnya taman bacaan bagi masyarakat. Hampir 92\% masyarakat paham dan mendukung perintisan taman baca di lingkungannya, sedangkan sisanya menjawab tidak tahu.

Sebagian besar masyarakat menyatakan bahwa keberadaan taman baca akan sangat penting karena bisa menjadi tempat bagi warga untuk mengisi waktu luang sembari menambah wawasan. Masyarakat juga berharap dengan adanya taman baca, semangat anak-anak untuk belajar membaca dapat semakin meningkat sehingga angka buta aksara diharapkan bisa semakin menurun. Para pengajar di KB Tunas Merapi juga berharap dengan adanya taman baca, jendela berpikir masyarakat terutama generasi muda dapat semakin terbuka lebar sehingga masyarakat akan semakin termotivasi untuk menempuh pendidikan setinggi mungkin.

Penjajakan minat baca masyarakat dilakukan dengan bekerja sama dengan Dompet Sejuta Harapan (DSH) Klaten untuk mengadakan perpustakaan keliling tanggal 1 Agustus 2017 (Gambar 1). Anak-anak terpantau sangat antusias terhadap buku-buku bacaan dan merekasangat menantikan taman baca yang tetap di desa. Hal ini menunjukkan bahwa minat baca masyarakat cukup tinggi sehingga keberadaan taman baca yang bersifat menetap diperlukan oleh masyarakat.

Volume 2, Number 1, Mei 2018| 74

Inisiasi Taman Baca Tunas Merapi sebagai Upaya Mencetak Generasi Gemar Membaca di Dusun Druwak Desa Logede Kecamatan Karangnongko Klaten 


\section{ENGAGEMENT}

Gurnal Pengabdian Kepada Masyarakat

ISSN: 2579-8375 (Print)

ISSN: 2579-8391 (Online)
This work is licensed under a Creative Commons

Attribution-ShareAlike 4.0 International License.

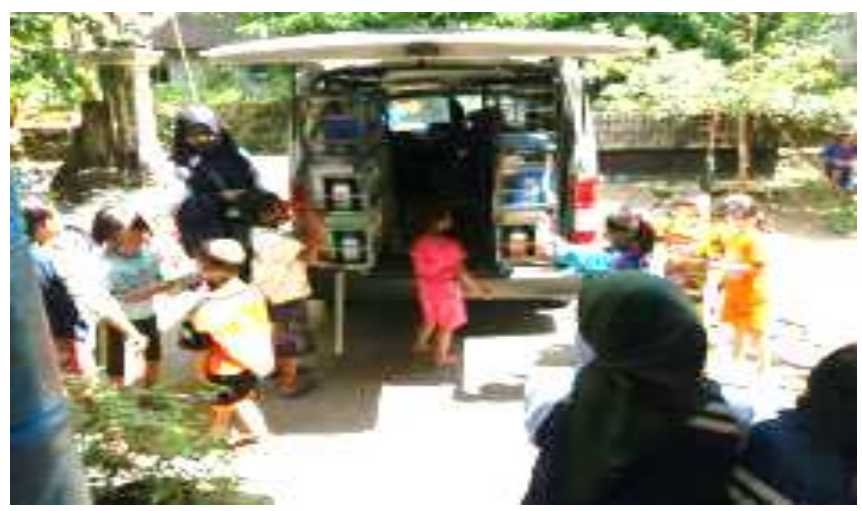

Gambar 1. Antusiasme anak-anak membaca melalui perpustakaan keliling (1/8/2017)

\section{Pembangunan Taman Baca}

Pembangunan taman baca semi permanen ini dilakukan dan dibantu oleh para pemuda karang taruna di desa Logede. Hal ini menunjukkan adanya kepedulian yang tinggi dari masyarakat desa terhadap aktivitas literasi (Gambar 2). Pembangunan taman baca yang ini berada di area KB Tunas Merapi ini berada di lokasi yang sangat strategis dengan rumah warga sehingga

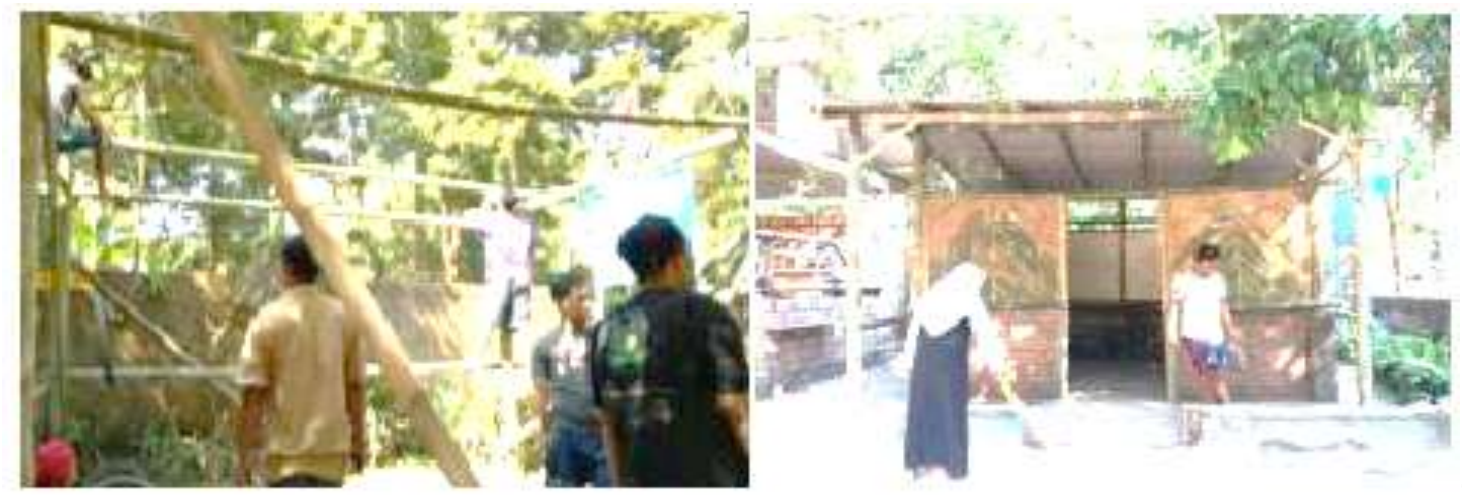

Gamba

\section{r2. Pembangunan fisik taman baca Tunas Merapi}

nantinya diharapkan akan mudah dijangkau oleh setiap masyarakat yang ingin membaca.

Kegiatan pembuatan dan penyiapan rak-rak buku yang nantinya akan digunakan sebagai tempat buku-buku di taman baca Tunas Merapi (Gambar 3). Rak-rak yang digunakan beragam mulai dari yang terbuat dari tripleks dan bambu yang dibuat dan dikreasikan bersama anak-anak dusun Druwak, desa Logede.

Volume 2, Number 1, Mei 2018| 75 Inisiasi Taman Baca Tunas Merapi sebagai Upaya Mencetak Generasi Gemar Membaca di Dusun Druwak Desa Logede Kecamatan Karangnongko Klaten 


\section{ENGAGEMENT}

Gurnal Pengabdian Kepada Masyarakat

ISSN: 2579-8375 (Print)

ISSN: 2579-8391 (Online)

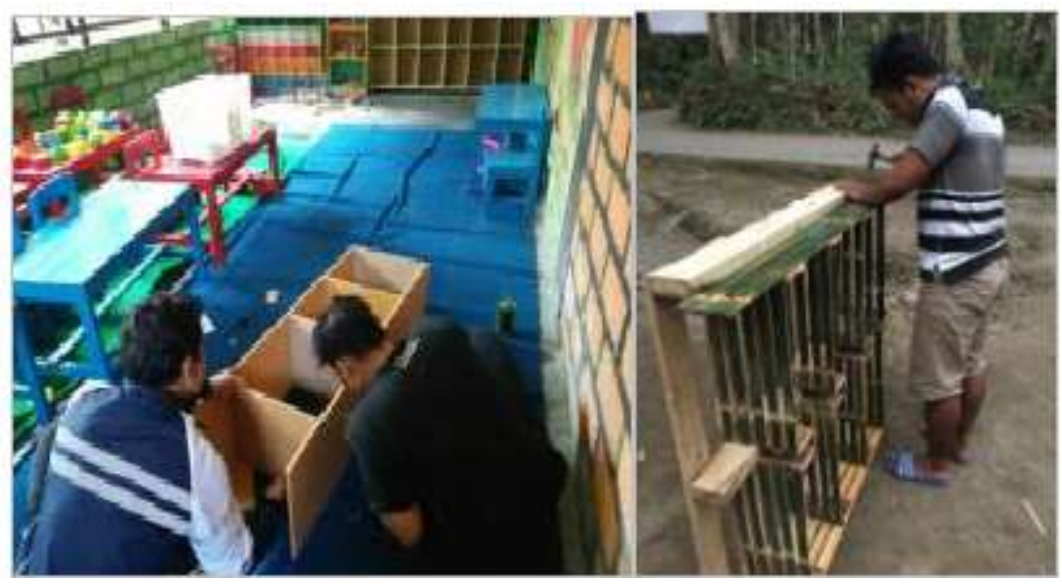

Gambar 3. Proses penyiapan rak-rak buku

Beberapa usaha untuk membuat daya tarik taman baca ini meningkat adalah dengan membuat tirai bertema (ikan dan laut), membuat hiasan gantung, logogram dan logitype. Kegiatan tersebut dilakukan oleh anak-anak KB yang didampingi oleh tim pengabdian.

\section{Pengadaan Buku Bacaan}

Pengadaan bahan bacaan di taman baca Tunas Merapi ini dilakukan dengan pengadaan program Donasi Buku untuk Merapi. Melalui program ini dikumpulkan buku-buku bacaan dari berbagai sumber mulai dari buku baru hingga bekas yang masih layak baca dan berhasil memperoleh kurang lebih 400 buku yang terdiri dari berbagai subjek, di antaranya buku bacaan anak, buku pendidikan, novel, buku agama, dan majalah.

Taman baca juga telah dilengkapi dengan alat peraga pembelajaran matematika, meliputi bangun datar, bangun ruang, rumus untuk mencari luas dan volume untuk anak-anak TB Tunas Merapi. Tim pengabdian telah membuat alat edukatif dan menarik agar matematika menjadi mudah dipahami. Selain itu, beragam aplikasi pembelajaran dan bermain berbasis Flash berupa CD menjadi koleksi taman baca (Gambar 4). Aplikasi pembelajaran dan permainan adalah permainan membuat bioetanol dari limbah buah (Arifa, 2014) dan permainan masyarakat gobag sodor (Putri, 2016). Aplikasi ini dapat menjadi sarana pembelajaran alternatif yang tersedia di taman baca dan dapat ditayangkan lewat layar proyektor.

Volume 2, Number 1, Mei 2018|76 Inisiasi Taman Baca Tunas Merapi sebagai Upaya Mencetak Generasi Gemar Membaca di Dusun Druwak Desa Logede Kecamatan Karangnongko Klaten 


\section{ENGAGEMENT}

Gurnal Pengabdian Kepada Masyarakat

ISSN: 2579-8375 (Print)

ISSN: 2579-8391 (Online)
This work is licensed under a Creative Commons

Attribution-ShareAlike 4.0 International License.

CC BY SA

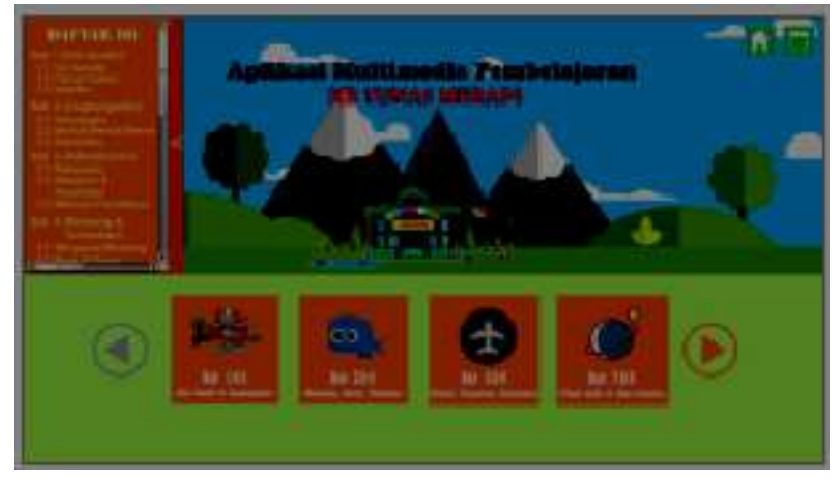

Gambar 4. Tampilan flash pembelajaran KB Tunas Merapi

\section{Pengolahan Koleksi Taman Baca}

Proses pengolahan koleksi taman baca yang telah dilakukan meliputi klasifikasi buku untuk mengelompokkan jenis-jenis buku sesuai dengan subjek masing-masing, inventarisasi dan penyajian koleksi buku di rak (Gambar 5). Klasifikasi ditujukan agar dapat memudahkan bagi para pengunjung taman baca untuk memilih buku bacaan yang diinginkan sesuai dengan prasyarat ruang baca (Ranganathan, 1931). Dengan pengelolaan tersebut, taman bacaan masyarakat diharapkan dapat membantu masyarakat dalam rangka menambah ilmu pengetahuan, pengembangan daya imajinasi dan kreativitas, pencerahan diri, serta pembentukan karakter dengan moralitas yang terpuji sejak dini (Sobri, 2010).
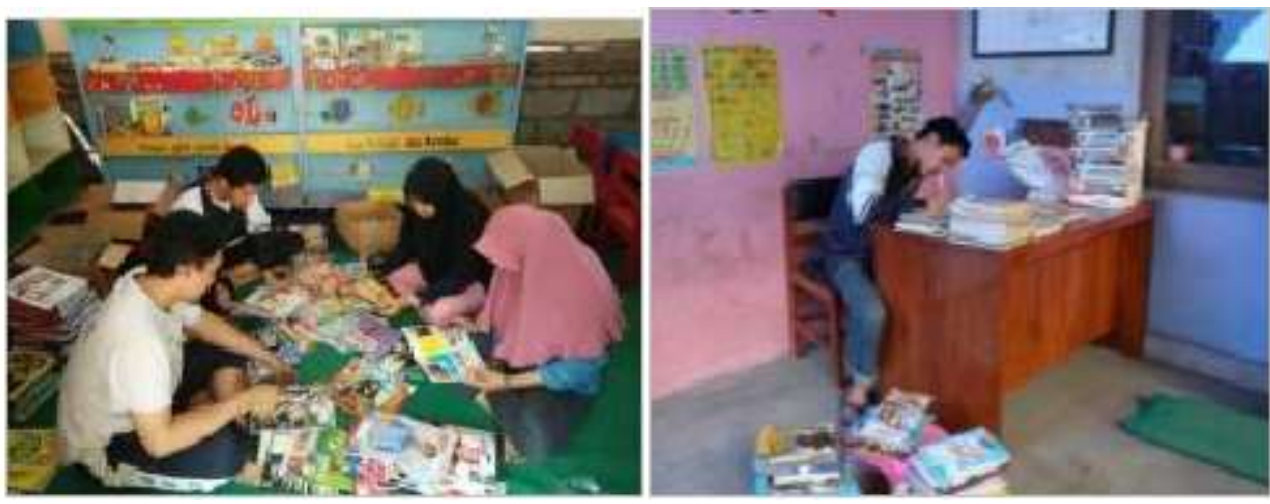

Gambar 5. Kegiatan pengolahan koleksi taman baca

Volume 2, Number 1, Mei 2018| 77

Inisiasi Taman Baca Tunas Merapi sebagai Upaya Mencetak Generasi Gemar Membaca di Dusun Druwak Desa Logede Kecamatan Karangnongko Klaten 


\section{Kesimpulan}

Pendidikan dan gerakan layanan bacaan berupa perintisan Taman Baca Tunas Merapi telah dilakukan dalam upaya membentuk masyarakat yang gemar membaca. Taman baca ini telah memenuhi unsur sebagai taman bacaan masyarakat dengan tersedia buku dan koleksi lainnya serta dapat diakses oleh semua anggota masyarakat. Koleksi dalam bentuk lainnya juga masih terus ditambah. Materi atau koleksi juga sudah diklasifikasikan sesuai dengan subjeknya. Dengan adanya taman baca ini diharapkan hanya gemar membaca saja namun juga mampu membuka pikirannya seluas mungkin dalam melihat dunia dan melek pendidikan sehingga memunculkan motivasi yang kuat dari dalam diri masing-masing untuk menjadi individu yang lebih berkembang dan lebih baik.

\section{Ucapan Terima Kasih}

Kegiatan pengabdian masyarakat ini didanai oleh Direktorat Riset dan Pengabdian Masyarakat Direktorat Jenderal Penguatan Riset dan Pengembangan Kementerian Riset, Teknologi dan Pendidikan Tinggi Tahun 2017.

\section{Daftar Referensi}

Kamah, Idris dkk., "Pedoman Pembinaan Minat Baca", Jakarta: Perpustakaan Nasional RI, 2002.

Kamsul, Khotijah. "Strategi Pengembangan Minat dan Gemar membaca". 2011. Diakses: 16 Oktober 2017. http://www.academia.edu/download/51918409/STRATEGI_PENGEMBANGAN_M INAT_BACA.pdf

Kementrian Pendidikan dan Kebudayaan. "Petunjuk Teknis Pengajuan dan Pengelolaan Taman Bacaan Masyarakat Bantuan Perluasan dan Penguatan Taman Bacaan Masyarakat (TBM)". Jakarta: Direktorat Pembinaan Pendidikan Masyarakat Direktorat Jenderal Pendidikan Anak Usia Dini, Nonformal, dan Informal, 2012.

Arikunto, Suharsimi. "Prosedur Penelitian: Suatu Pendekatan Praktek". Edisi Revisi. Jakarta: Rineka Cipta, 2010.

Sobri. Dkk. "Pengelolaan Pendidikan". Yogyakarta: Multi Pressindo, 2009.

Ranganahan, S. R. "The Five Laws of Library Science". 1931. Diambil dari https://babel.hathitrust.org/cgi/pt?id=uc1.\$b99721. [Accessed 16 Oct. 2017]

Arifa, N., Isnanto, R. R., and Nurhayati, O. D., 2014. Perancangan Permainan "Membuat Bioetanol dari Limbah Buah" Menggunakan Adobe Flash CS3. Jurnal Teknologi dan Sistem Komputer, [Online] Volume 2(1), pp. 87-95. [Accessed 16 Oct. 2017]. 


\section{ENGAGEMENT}

Gurnal Pengabdian Kepada Masyarakat

ISSN: 2579-8375 (Print)

ISSN: 2579-8391 (Online)
This work is licensed under a Creative Commons

Attribution-ShareAlike 4.0 International License.

Putri, B. D. C., Kridalukmana, R., and Widianto, E. D., 2016. Perancangan Aplikasi Permainan Multiplayer Gobak Sodor Berbasis Flash Di Lingkup Jaringan Lokal. Jurnal Teknologi dan Sistem Komputer, [Online] Volume 4(2), pp. 259-265. doi:https://doi.org/10.14710/jtsiskom.4.2.2016.259-265 [Accessed 16 Oct. 2017]. 